\title{
Corrosion Studies of Pine-Derived Bio-Oil and Heavy Fuel Oil Blends
}

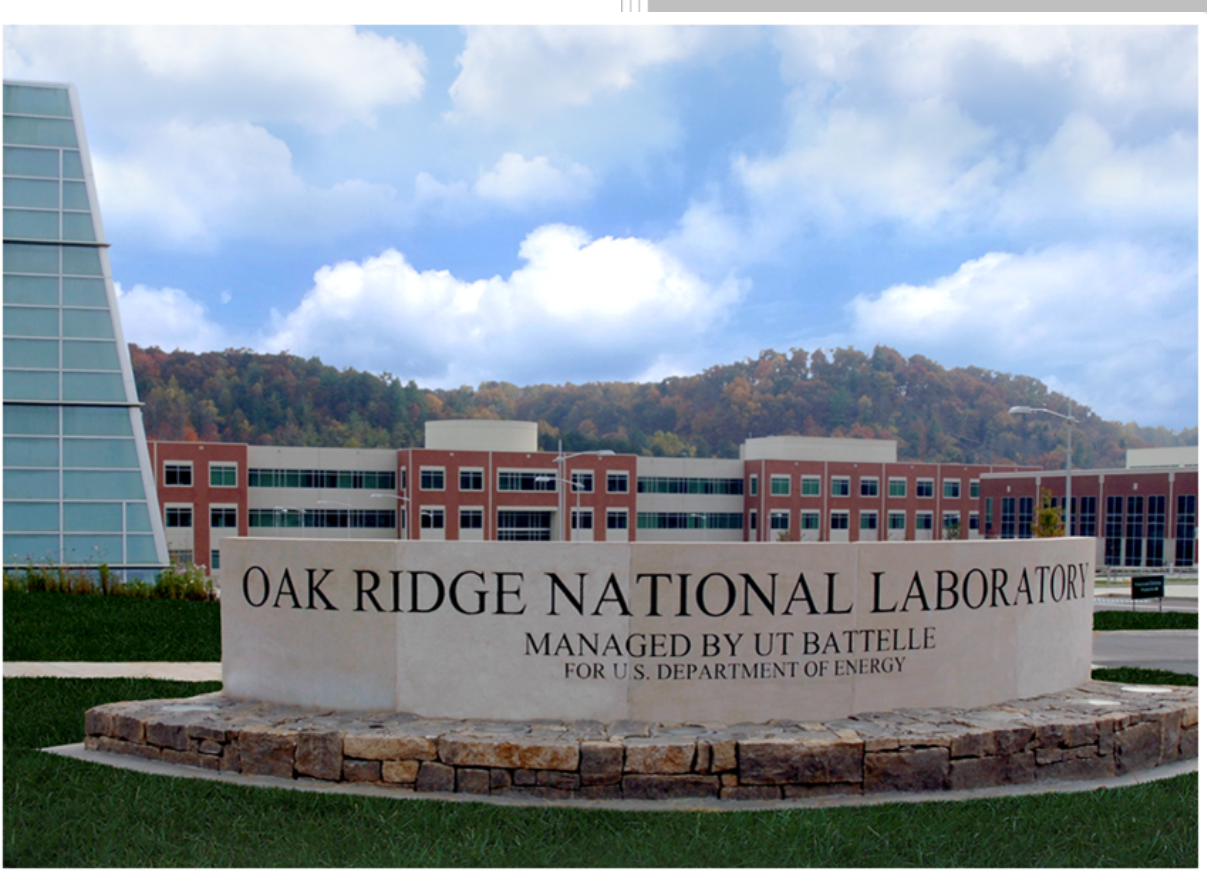

G. L. Warrington

J. R. Keiser

R.M. Connatser

Approved for public release. Distribution is unlimited. 


\section{DOCUMENT AVAILABILITY}

Reports produced after January 1, 1996, are generally available free via US Department of Energy (DOE) SciTech Connect.

Website www.osti.gov

Reports produced before January 1, 1996, may be purchased by members of the public from the following source:

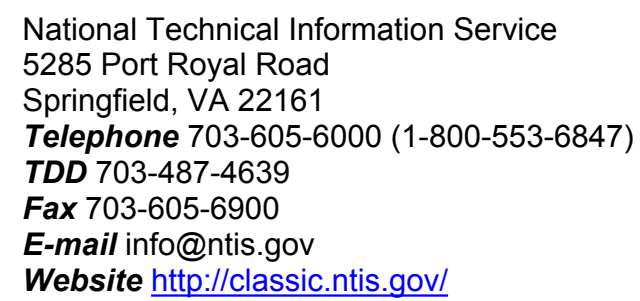

Reports are available to DOE employees, DOE contractors, Energy Technology Data Exchange representatives, and International Nuclear Information System representatives from the following source:

Office of Scientific and Technical Information

PO Box 62

Oak Ridge, TN 37831

Telephone 865-576-8401

Fax 865-576-5728

E-mail reports@osti.gov

Website http://www.osti.gov/contact.html

This report was prepared as an account of work sponsored by an agency of the United States Government. Neither the United States Government nor any agency thereof, nor any of their employees, makes any warranty, express or implied, or assumes any legal liability or responsibility for the accuracy, completeness, or usefulness of any information, apparatus, product, or process disclosed, or represents that its use would not infringe privately owned rights. Reference herein to any specific commercial product, process, or service by trade name, trademark, manufacturer, or otherwise, does not necessarily constitute or imply its endorsement, recommendation, or favoring by the United States Government or any agency thereof. The views and opinions of authors expressed herein do not necessarily state or reflect those of the United States Government or any agency thereof. 
Materials Science and Technology Division

\title{
Corrosion Studies of Pine-Derived Bio-Oil and Heavy Fuel Oil Blends
}

\author{
G. L. Warrington \\ J.R. Keiser \\ R.M. Connatser
}

Date Published: February 2020

Prepared by

OAK RIDGE NATIONAL LABORATORY

Oak Ridge, TN 37831-6283

managed by

UT-BATTELLE, LLC

for the

US DEPARTMENT OF ENERGY

under contract DE-AC05-00OR22725 



\section{CONTENTS}

ABSTRACT

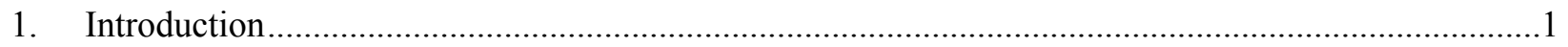

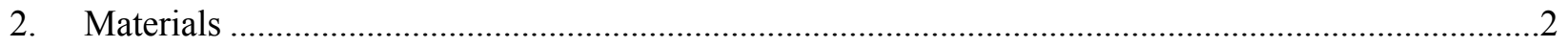

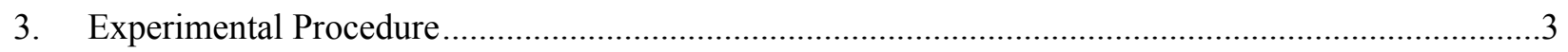

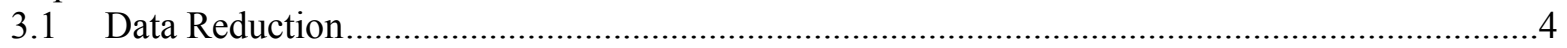

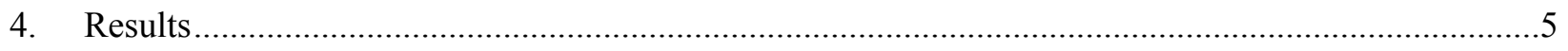

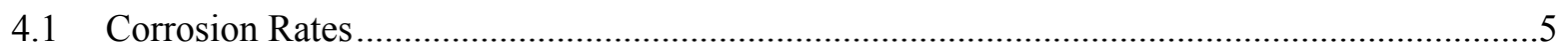

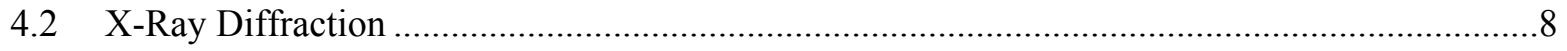

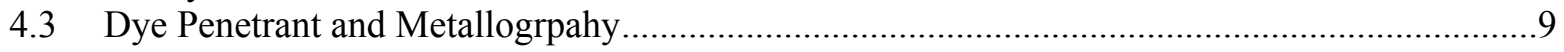

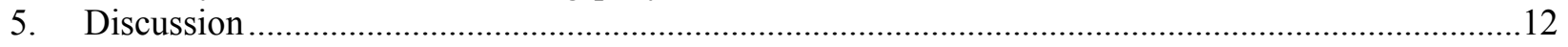

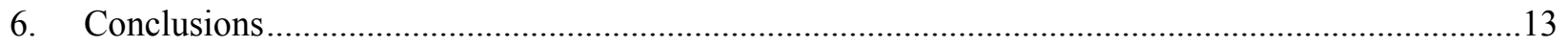

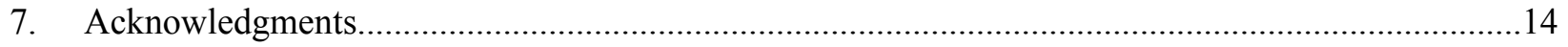

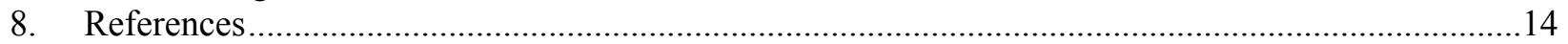




\begin{abstract}
To reduce the amount of greenhouse gas produced from the combustion of petroleum fuels, renewable liquid fuels are needed. Pyrolysis of biomass provides a means to produce liquid fuels to displace current petroleum products. However, common ferrous alloys are susceptible to high corrosion rates when exposed to bio-oil. This study analyzes the effects of blending bio-oil derived from loblolly pine with heavy fuel oil added to reduce corrosion of common structural alloys. Laboratory corrosion studies of six different blends of bio-oil/heavy fuel oil were performed for 1,000 hours at $50^{\circ} \mathrm{C}$. Chemical characterization was also performed to determine the total acid content of each blend. Post-exposure characterizations such as changes in weight, X-ray diffraction, dye penetrant testing, and metallography were performed to provide more insight into the corrosion mechanism of bio-oil/heavy fuel oil blends. We hypothesized that the corrosion rates of ferrous alloys would increase with an increase in bio-oil concentration. The results of these characterization and corrosion studies confirmed this hypothesis and will be reported.
\end{abstract}

\title{
1. INTRODUCTION
}

The desire to reduce greenhouse gas emissions has driven the search for renewable energy solutions. Many renewable approaches such as solar, wind, and water can create electricity. However, liquid fuels are required for the internal combustion processes in jet, diesel, and automotive engines and for chemical processing. Liquefaction of biomass is a renewable solution that produces a liquid product potentially replace petroleum-based fuels [11]. The compounds can be used as produced or subjected to further processing to make products of higher value $[1,8]$.

However, biomass contains high amounts of oxygen which results in the production of various organic oxygenates [2,9]. Acidic compounds such as carboxylic acids, formic, and acetic acids ( $\mathrm{pH} 2-3$ range) are present in bio-oils in high concentrations [9]. Other organic compounds containing sulfur, nitrogen, and chlorine are also present in liquid biofuels [2]. The combination of these organic compounds results in the degradation of many metallic containment materials. Current petroleum refineries primarily use carbon steels for process vessels because they are cost-effective, but previous studies have shown that bio-oils are highly corrosive to such steels $[1,10]$. Therefore, the identification of corrosion resistant alloys is essential to the commercialization of biomass liquefaction technologies if co-firing with petroleum-based fuels is to be accomplished.

One approach to the initial commercialization of biomass liquefaction technologies is to blend bio-oils with petroleum products such as heavy fuel oil (HFO). Such blending will reduce the use of nonrenewable HFO, and potentially mitigate the detrimental impacts of bio-oils on corrosion resistance. This study evaluates the corrosivity of HFO/bio-oil mixtures as an increasing percentage of bio-oil is added. Generally, the Aqueous Modified Total Acid Number (AMTAN) increases as the concentration of bio-oil increases [3]. The relationship between the acidity of the HFO/bio-oil blends and the corrosion rates are being characterized to understand the relationship between the concentrations of corrosive organic compounds in the liquid and the corrosion mechanisms associated with the oxygenates. The corrosion rates of each alloy are expected to increase as the concentration of bio-oil in the blend rises due to the increase in acidity of the liquid.

Our current project focuses on assessing the corrosion resistance of structural materials involved in the storage of these biomass-derived oils and includes laboratory corrosion studies of exposed samples in various concentrations of bio-oil and HFO blends. This report describes corrosion rates of five alloys (C1018, F22, 409, 304L, and 316L) with biomass liquefaction products/HFO blends to provide 
information required for the selection of the most durable, lowest cost materials. The information will help enable the commercialization of biomass liquefaction technologies.

\section{MATERIALS}

Five steels (C1018, F22, 409, 304L, and 316L) were selected for exposure based on the cost of the material and the increasing chromium content of each alloy. The nominal compositions of each alloy are listed in Table 1. The hypothesis stated that higher chromium alloys would be more corrosion resistant than lower chromium or carbon steels. Two alloys contain molybdenum to aid in improved resistance to localized corrosion [4]. However, with a higher chromium and molybdenum content the cost of the material increases.

Table 1. Nominal weight percent compositions of five alloys used in corrosion testing.

\begin{tabular}{|l|c|c|c|c|c|c|}
\hline Alloy & Fe (\%) & Cr (\%) & Ni (\%) & Mo (\%) & Mn (\%) & C (\%) \\
\hline Carbon steel & Balance & ---- & ---- & --- & 1.0 & 0.13 \\
\hline 21\% Cr-1 Mo steel & Balance & 2.25 & ---- & 1.0 & 0.4 & 0.1 \\
\hline 409 stainless steel & Balance & 11 & ---- & ---- & 0.3 & 0.015 \\
\hline 304L stainless steel & Balance & 18.3 & 9.0 & ---- & 1.7 & 0.02 \\
\hline 316L stainless steel & Balance & 16.4 & 10.2 & 2.1 & 1.6 & 0.02 \\
\hline
\end{tabular}

Six separate blends of HFO and oils derived form the pyrolysis of loblolly pine were studied. The bio-oil was prepared by the National Renewable Energy Laboratory (NREL) using loblolly pine and loblolly pine residue harvested in 2018 as the feedstock. NREL produced the bio-oil using a high temperature pyrolysis technique [5]. A total acid number determination was calculated for each blend using a modification of the ASTM D664 technique designed for petroleum-based oils [6]. An aqueous rather than organic solvent extraction is used because this is considered to be a better means of extracting the more polar acid compounds of the bio-oil. The composition of each blend along with the AMTAN values are displayed in Table 2.

Table 2. Blends for Corrosion Testing at $50^{\circ} \mathrm{C}$ measured as mass percent.

\begin{tabular}{|c|c|c|}
\hline Blend 0 & $100 \%$ Heavy Fuel Oil & AMTAN: 2 \\
\hline Blend 1 & $92 \%$ HFO and 8\% Loblolly Pine Bio-Oil & AMTAN: 3 \\
\hline Blend 2 & $81 \%$ HFO and 19\% Loblolly Pine Bio-Oil & AMTAN: 13 \\
\hline Blend 3 & $75 \%$ HFO and 25\% Loblolly Pine Bio-Oil & AMTAN: 18 \\
\hline Blend 4 & $50 \%$ HFO and 50\% Loblolly Pine Bio-Oil & AMTAN: 35 \\
\hline Blend 5 & $100 \%$ Loblolly Pine Bio-Oil & AMTAN: 112 \\
\hline
\end{tabular}




\section{EXPERIMENTAL PROCEDURE}

Test systems consisted of a heating mantle with a 3,000 $\mathrm{ml}$ round-bottom glass flask placed inside a heating sleeve (Figure 1). The top of the container was sealed with an O-ring and a glass cover held in place by a C-clamp. A thermocouple and water-cooled condenser are inserted into the ports of the glass cover.

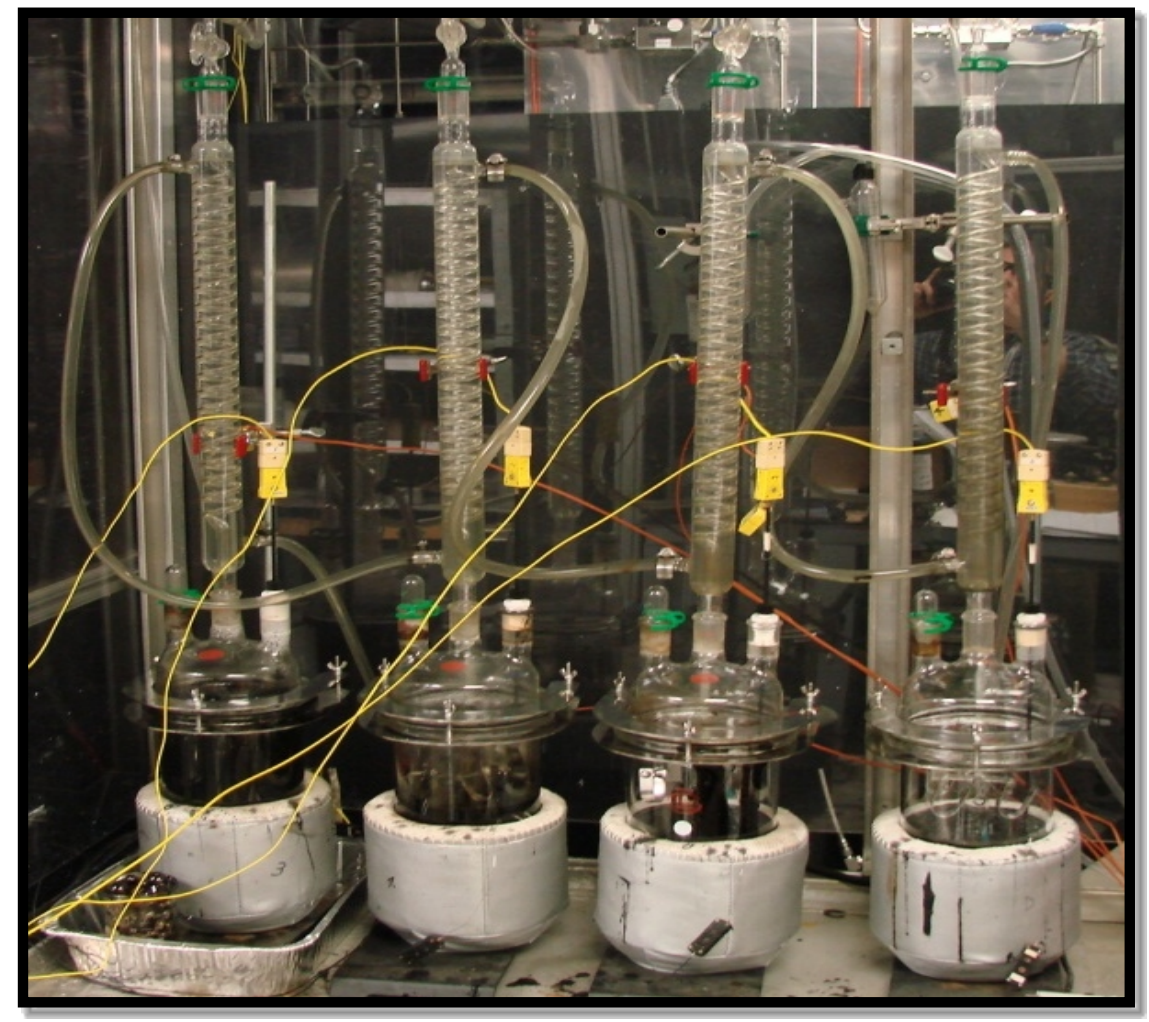

Figure 1. Laboratory setup for heating bio-oil blends to $50^{\circ} \mathrm{C}$ for sample immersion.

Samples were cleaned for immersion testing by placing them in an acetone bath, sonicating for 20 minutes, and then moving them to a methanol bath for an additional 20 minutes. Once cleaned, the initial mass of the samples was recorded.

The prepared samples were exposed in both fluid and vapor conditions. Five coupons and five U-bends of each alloy were placed on a glass "tree" in the vapor space location. The remaining five coupons and five U-bends were placed in the fluid immersion space as shown in Figure 2. Once loaded, the "tree" assembly was placed inside the glass container. The container was filled with approximately 2 liters of $\mathrm{HFO} /$ bio-oil blend to the height required to immerse the fluid samples completely. Each container was filled with an argon cover gas to prevent further oxidation and the condenser was chilled to $15.0^{\circ} \mathrm{C}$ with flowing deionized water. 


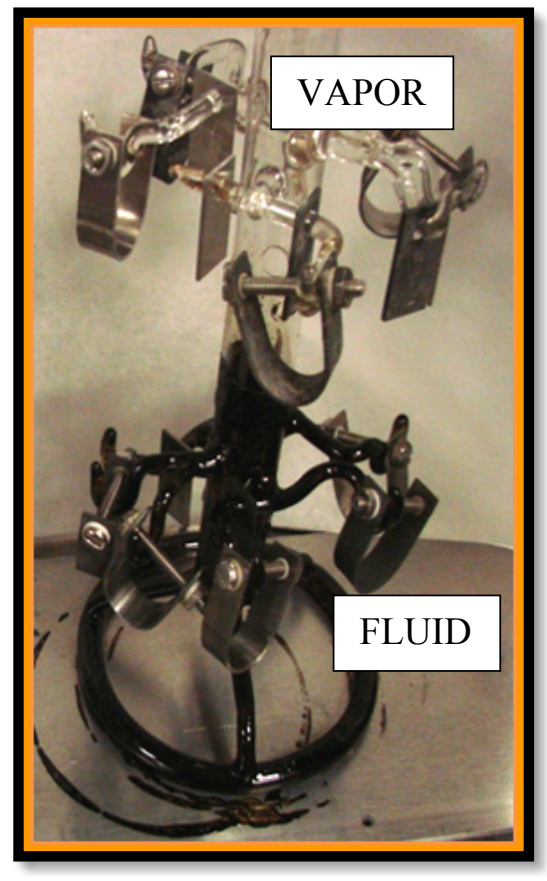

Figure 2. Glass "tree" holding U-bend and coupon samples in the vapor and fluid locations.

Samples were exposed for an initial period of 250 hours at $50^{\circ} \mathrm{C}$, then they were cleaned, weighed, and reinstalled in the test system for another 250 hours of exposure. Following cleaning and weighing after the second exposure period, the samples were exposed for an additional 500 hours for a total exposure of 1,000 hours at $50^{\circ} \mathrm{C}$. After each cleaning and weighing, the corrosion rates for each sample were calculated.

The samples were cleaned by sonicating the samples in an acetone bath for 60 minutes. They were then removed and washed by hand with dish soap until all visible corrosion product and oil residue was removed.

Once the samples were exposed for a total of 1,000 hours, the carbon steel and 2.25Cr-1Mo coupons were removed from both the fluid and vapor space. Prior to cleaning, the coupons were brought to x-ray diffraction (XRD) for analysis. The XRD measurements were taken with continuous $\theta-2 \theta$ scans from nominally 5 to $45^{\circ} 2 \theta$ using MoK $\alpha$ radiation. All scans used $1 / 4^{\circ}$ fixed slit, $12^{\circ}$ anti-scatter slit, 0.02 soller slits coupled with a $10 \mathrm{~mm}$ mask.

After 1,000 hours of exposure, the carbon steel, 2.25Cr-1Mo steel, and 409 stainless steel U-bends were cleaned prior to metallographic examination and dye penetrant testing. The metallographic examinations were prepared by removing a cross section of the U-bend for polishing prior to taking the micrographs (Figure 3). 


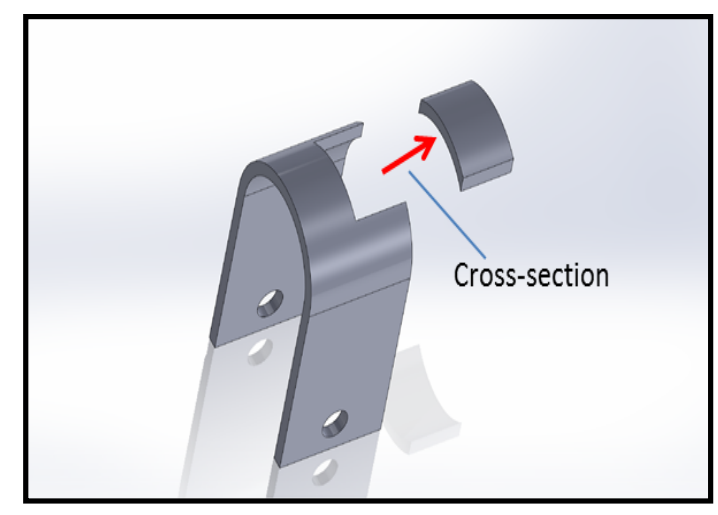

Figure 3. Sketch showing how metallography samples were collected from the U-bend samples.

\subsection{Data Reduction}

The corrosion rates $(C R)$ were calculated for each sample using equation (1) to measure of the compatibility of each steel in the bio-oil environment.

$$
C R\left(\frac{m m}{y r}\right)=\frac{8766\left(\frac{h}{y r}\right) * 10\left(\frac{m m}{c m}\right) *(I W-F W)(g m)}{S A(c m 2) * t(h) * \rho\left(\frac{g m}{c m 3}\right)}
$$

The variable $I W$ represents the initial mass of the sample in grams, and $F W$ represents the final mass of the sample in grams. $S A$ is the surface area of the coupon or U-bend in square centimeters and $\rho$ is the density of the material in grams per cubic centimeter. The exposure time is indicated by t. Rates above .01 millimeters per year $(\mathrm{mm} / \mathrm{yr})$ are considered unacceptable for structural alloy lifespans in this study.

\section{RESULTS}

\subsection{CORROSION RATES}

Corrosion tests with $100 \%$ loblolly pine bio-oil consistently show that the oils are corrosive to carbon steel and 2.25Cr-1Mo steel, along with 409 stainless steel in the fluid (Table 3). These alloys contain less than $10-12 \%$ chromium. The 300 series stainless steels contain between $16-19 \%$ chromium, as well as nickel (and for 316L molybdenum) and show negligible corrosion in raw bio-oil.

Diluting loblolly pine bio-oil with HFO resulted in lower corrosion rates for all alloys compared to $100 \%$ bio-oil (Table 3). Blend zero, which contains 100\% HFO, serves as a baseline comparison. All alloys demonstrated strong corrosion resistance to blend zero in both the vapor space and when immersed in the fluid. The corrosion rate for carbon steel was acceptable in blend zero exposed in the vapor space, but unacceptable corrosion rates were calculated for carbon steel samples in the vapor space for the remaining five blends. Carbon steel immersed in blends 1 (8\% bio-oil) and 2 (19\% bio-oil) showed acceptable corrosion resistance, with higher rates in the vapor space. $2.25 \mathrm{Cr}-1 \mathrm{Mo}$ steel exposed to blend 3 ( $25 \%$ biooil) caused an unacceptable corrosion rate for $2.25 \mathrm{Cr}-1 \mathrm{Mo}$ steel in the vapor space only. The corrosion rate rose above the acceptable level for the 409 stainless steel samples exposed to blend 4 (50\% bio-oil) in the fluid space. Corrosion resistance diminished when 409 was exposed to blend 5 (100\% bio-oil) for 
both regions. The 304L and 316L stainless steels retained low corrosion rates while exposed to all six blends.

Table 3: Calculated corrosion rates based on 1,000 hour exposure of selected alloy coupons suspended above the surface of the oil and immersed in the $50^{\circ} \mathrm{C}$ bio-oil.

\begin{tabular}{|c|c|c|c|c|c|}
\hline & $\begin{array}{c}\text { Carbon Steel } \\
(\mathrm{mm} / \mathrm{yr})\end{array}$ & $\begin{array}{c}\text { 2.25Cr-1Mo } \\
\text { steel } \\
(\mathrm{mm} / \mathrm{yr})\end{array}$ & $\begin{array}{l}409 \text { Stainless } \\
(\mathrm{mm} / \mathrm{yr})\end{array}$ & $\begin{array}{c}\text { 304L } \\
\text { Stainless } \\
(\mathrm{mm} / \mathrm{yr})\end{array}$ & $\begin{array}{c}\text { 316L } \\
\text { Stainless } \\
(\mathrm{mm} / \mathrm{yr})\end{array}$ \\
\hline \multicolumn{6}{|c|}{ Blend $0(100 \% \mathrm{HFO})$} \\
\hline Vapor & $<.01$ & $<.01$ & $<.01$ & $<.01$ & $<.01$ \\
\hline Fluid & $<.01$ & $<.01$ & $<.01$ & $<.01$ & $<.01$ \\
\hline \multicolumn{6}{|c|}{ Blend 1 (92\% HFO and 8\% Loblolly Pine Bio-Oil) } \\
\hline Vapor & .019 & $<.01$ & $<.01$ & $<.01$ & $<.01$ \\
\hline Fluid & $<.01$ & $<.01$ & $<.01$ & $<.01$ & $<.01$ \\
\hline \multicolumn{6}{|c|}{ Blend 2 (81\% HFO and 19\% Loblolly Pine Bio-Oil) } \\
\hline Vapor & .021 & $<.01$ & $<.01$ & $<.01$ & $<.01$ \\
\hline Fluid & $<.01$ & $<.01$ & $<.01$ & $<.01$ & $<.01$ \\
\hline \multicolumn{6}{|c|}{ Blend 3 (75\% HFO and 25\% Loblolly Pine Bio-Oil) } \\
\hline Vapor & .042 & .036 & $<.01$ & $<.01$ & $<.01$ \\
\hline Fluid & .018 & $<.01$ & $<.01$ & $<.01$ & $<.01$ \\
\hline \multicolumn{6}{|c|}{ Blend $4(50 \%$ HFO and 50\% Loblolly Pine Bio-Oil) } \\
\hline Vapor & .018 & .013 & $<.01$ & $<.01$ & $<.01$ \\
\hline Fluid & .031 & .040 & .037 & $<.01$ & $<.01$ \\
\hline \multicolumn{6}{|c|}{ Blend 5 (100\% Loblolly Pine Bio-Oil) } \\
\hline Vapor & .339 & .478 & $<.01$ & $<.01$ & $<.01$ \\
\hline Fluid & 1.47 & 2.63 & 1.22 & $<.01$ & $<.01$ \\
\hline
\end{tabular}

The U-bend samples exhibited results similar to the coupons when exposed to the same blends of bio-oil (Table 4). Carbon steel showed high corrosion rates in all five bio-oil blends within the vapor space, but maintained acceptable rates when immersed in blends 1 and 2. While the 2.25Cr-1Mo steel coupon showed only significant corrosion in the vapor space for blend 3, the U-bend exhibited significant corrosion rates in both the vapor and fluid regions. The 409 stainless steel maintained low corrosion rates in blends 1,2, and 3, like the coupons. The corrosion rate for 409 stainless steel rose above the acceptable value in blend 4 while immersed in the fluid. The 304L and 316L stainless steel U-bends did not show significant corrosion rates in any of the bio-oil blends. 
Table 4: Calculated corrosion rates based on 1,000 hour exposure of selected alloy U-bends suspended above the surface of the oil and immersed in the $50^{\circ} \mathrm{C}$ bio-oil.

\begin{tabular}{|c|c|c|c|c|c|}
\hline & $\begin{array}{c}\text { Carbon Steel } \\
(\mathrm{mm} / \mathrm{yr})\end{array}$ & $\begin{array}{c}2.25 \mathrm{Cr}-1 \mathrm{Mo} \\
\text { steel } \\
(\mathrm{mm} / \mathrm{yr})\end{array}$ & $\begin{array}{l}409 \text { Stainless } \\
(\mathrm{mm} / \mathrm{yr})\end{array}$ & $\begin{array}{c}\text { 304L } \\
\text { Stainless } \\
(\mathrm{mm} / \mathrm{yr}) \\
\end{array}$ & $\begin{array}{c}\text { 316L } \\
\text { Stainless } \\
(\mathrm{mm} / \mathrm{yr})\end{array}$ \\
\hline \multicolumn{6}{|c|}{ Blend $0(100 \% \mathrm{HFO})$} \\
\hline Vapor & $<.01$ & $<.01$ & $<.01$ & $<.01$ & $<.01$ \\
\hline Fluid & $<.01$ & $<.01$ & $<.01$ & $<.01$ & $<.01$ \\
\hline \multicolumn{6}{|c|}{ Blend 1 (92\% HFO and 8\% Loblolly Pine Bio-Oil) } \\
\hline Vapor & .013 & $<.01$ & $<.01$ & $<.01$ & $<.01$ \\
\hline Fluid & $<.01$ & $<.01$ & $<.01$ & $<.01$ & $<.01$ \\
\hline \multicolumn{6}{|c|}{ Blend 2 (81\% HFO and 19\% Loblolly Pine Bio-Oil) } \\
\hline Vapor & .024 & $<.01$ & $<.01$ & $<.01$ & $<.01$ \\
\hline Fluid & $<.01$ & $<.01$ & $<.01$ & $<.01$ & $<.01$ \\
\hline \multicolumn{6}{|c|}{ Blend 3 (75\% HFO and 25\% Loblolly Pine Bio-Oil) } \\
\hline Vapor & .016 & .036 & $<.01$ & $<.01$ & $<.01$ \\
\hline Fluid & .011 & .077 & $<.01$ & $<.01$ & $<.01$ \\
\hline \multicolumn{6}{|c|}{ Blend 4 (50\% HFO and 50\% Loblolly Pine Bio-Oil) } \\
\hline Vapor & $<.01$ & .012 & $<.01$ & $<.01$ & $<.01$ \\
\hline Fluid & .034 & .040 & .034 & $<.01$ & $<.01$ \\
\hline \multicolumn{6}{|c|}{ Blend 5 (100\% Loblolly Pine Bio-Oil) } \\
\hline Vapor & .377 & .288 & .058 & $<.01$ & $<.01$ \\
\hline Fluid & 1.67 & 2.65 & .344 & $<.01$ & $<.01$ \\
\hline
\end{tabular}

The corrosion rates increased for carbon steel, 2.25Cr-1Mo steel, and 409 stainless steel as the mass percent of bio-oil increased (Figure 4-6), as was observed in the coupon and U-bend samples for all three alloys when immersed in the fluid. The data for the $2.25 \mathrm{Cr}-1 \mathrm{Mo}$ contain an outlier for the U-bend exposed to the $25 \%$ bio-oil blend, but this discrepancy could be due to the cleaning process of the sample. The corrosion rates for the coupon and U-bend samples are very similar to one another.

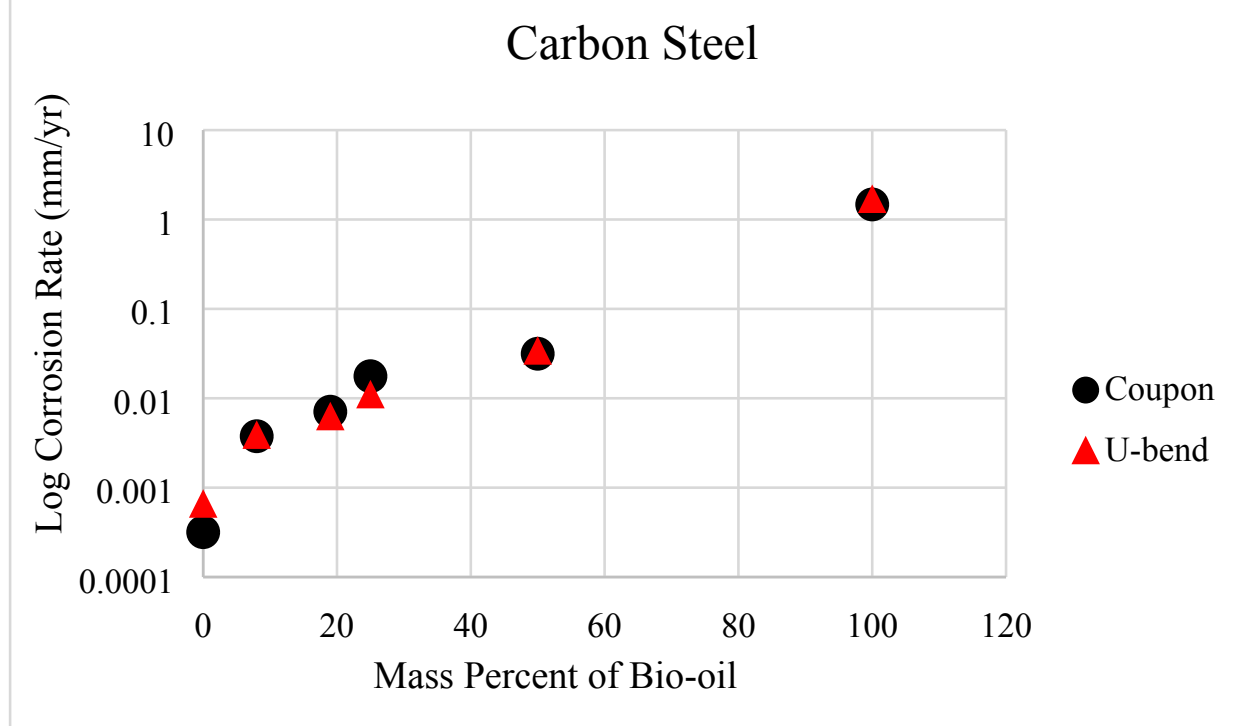

Figure 4. Corrosion rates of carbon steel samples immersed in blends 0-5 at $50^{\circ} \mathrm{C}$. 


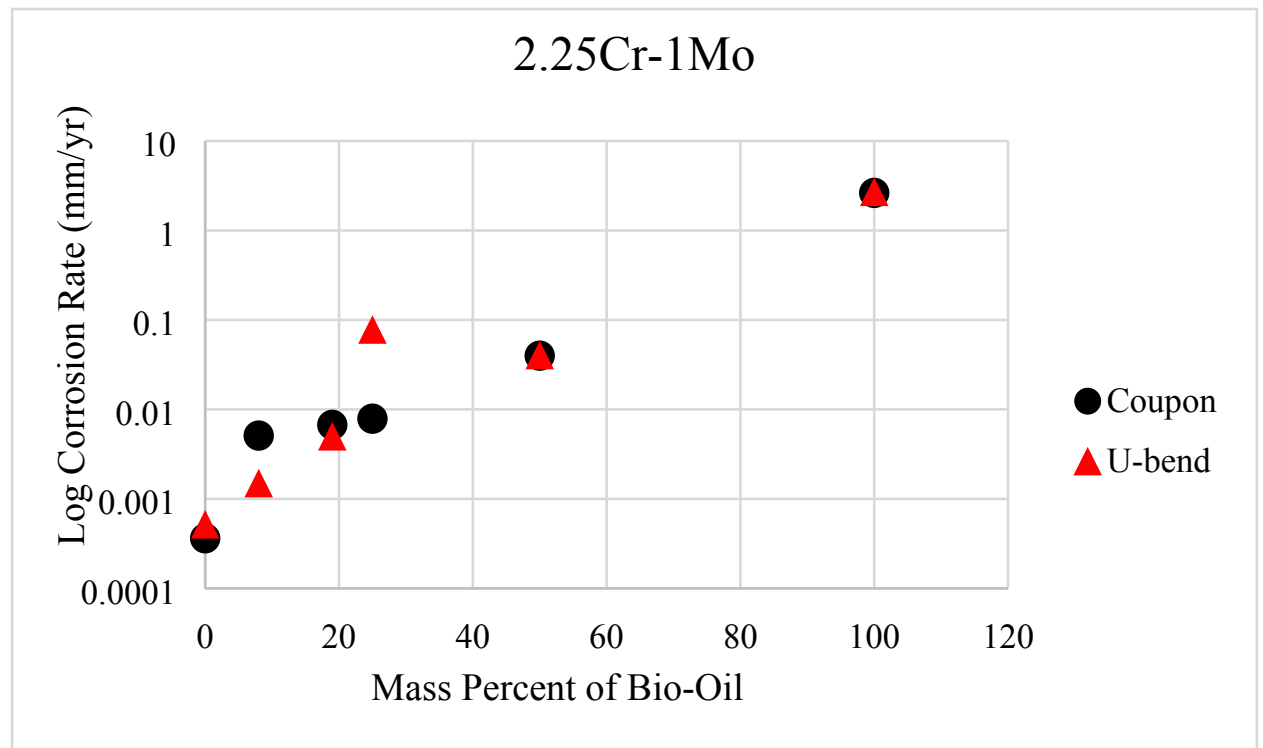

Figure 5. Corrosion rates of 2.25-1Mo steel samples immersed in blends $0-5$ at $50^{\circ} \mathrm{C}$.

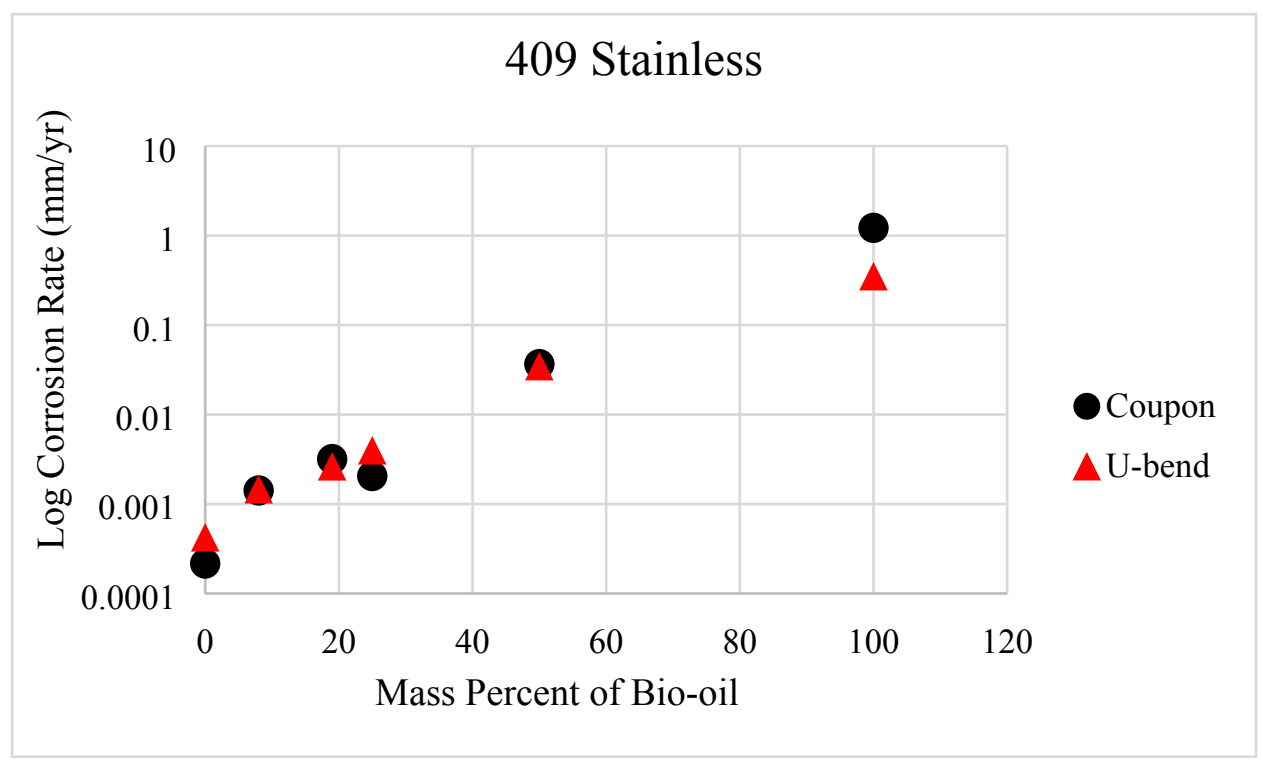

Figure 6. Corrosion rates of 409 stainless steel samples immersed in blends $0-5$ at $50^{\circ} \mathrm{C}$.

Corrosion rates for 304L and 316L stainless steels were less than 0.01 millimeters per year for blends $0-5$. Therefore, given the negligible corrosion rates, no meaningful association between bio-oil concentration and corrosion rate could be defined for 304L and 316L stainless steels.

\subsection{X-RAY DIFFRACTION}

The alloys that demonstrated the highest corrosion rates (carbon steel and $2.25 \mathrm{Cr}-1 \mathrm{Mo}$ ) were analyzed by XRD. Previous XRD analysis of laboratory corrosion studies identified iron formate hydrate $\left(\mathrm{Fe}(\mathrm{HCOO})_{2}\left(\mathrm{H}_{2} \mathrm{O}\right)_{2}\right)$ as a corrosion product that formed on the low chromium alloys [7]. The coupons 
exposed to the $8 \%$ and $19 \%$ bio-oil blends did not contain enough corrosion product on the surface to register peaks. The carbon steel coupon that was immersed in the $25 \%$ bio-oil blend showed the presence of iron formate hydrate on the surface. The $2.25 \mathrm{Cr}-1 \mathrm{Mo}$ steel coupons did not show any surface products for either the vapor space or fluid space locations in the $25 \%$ bio-oil blend 3 . Analysis of the carbon steel and $2.25-1 \mathrm{Mo}$ steel from the $50 \%$ and $100 \%$ blends showed strong evidence of iron formate hydrate on the surface of both the vapor samples and the fluid samples (Table 5).

Table 5. Summary of iron formate present on carbon steel and 2.25-1Mo steel coupons.

\begin{tabular}{|c|c|c|}
\hline & \multicolumn{2}{|c|}{ Iron Formate Present } \\
\hline & Carbon Steel & $2.25 \mathrm{Cr}-1 \mathrm{Mo}$ steel \\
\hline \multicolumn{3}{|c|}{ Blend 1 (92\% HFO and $8 \%$ Loblolly Pine Bio-Oil) } \\
\hline Vapor & None & None \\
\hline Fluid & None & None \\
\hline \multicolumn{3}{|c|}{ Blend 2 (81\% HFO and 19\% Loblolly Pine Bio-Oil) } \\
\hline Vapor & None & None \\
\hline Fluid & None & None \\
\hline \multicolumn{3}{|c|}{ Blend 3 (75\% HFO and 25\% Loblolly Pine Bio-Oil) } \\
\hline Vapor & None & None \\
\hline Fluid & Moderate & None \\
\hline \multicolumn{3}{|c|}{ Blend 4 (50\% HFO and 50\% Loblolly Pine Bio-Oil) } \\
\hline Vapor & Moderate & Moderate \\
\hline Fluid & Moderate & Moderate \\
\hline \multicolumn{3}{|c|}{ Blend 5 (100\% Loblolly Pine Bio-Oil) } \\
\hline Vapor & High & High \\
\hline Fluid & Moderate & Moderate \\
\hline
\end{tabular}

\subsection{DYE PENETRANT AND METALLOGRPAHY}

The U-bend samples from the fluid and vapor spaces of blends 3 (25\% bio-oil) and 5 (100\% bio-oil) were subjected to dye penetrant testing to look for evidence of stress corrosion cracking or stress accelerated corrosion. The 304L and 316L U-bends were not analyzed because there was little mass change/corrosion attack recorded for both groups. No group of U-bends showed visual crack formation after the dye penetrant test (Figure 7). 


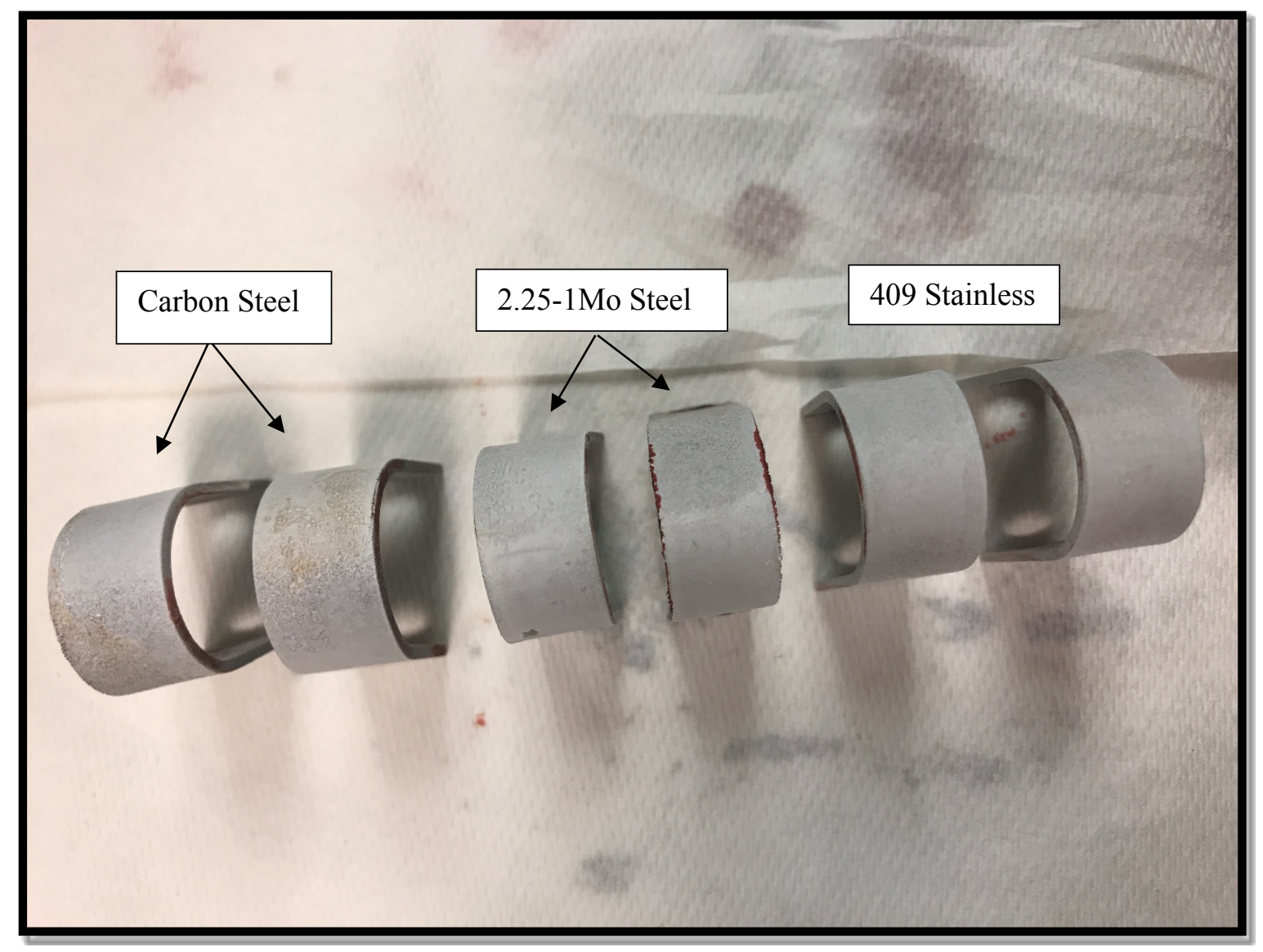

Figure 7. Dye penetrant test shows no signs of stress corrosion cracking in carbon steel, 2.25-1Mo steel, and 409 stainless steel from the fluid and vapor spaces of blend $5(100 \%$ bio-oil).

The same samples were taken for metallography preparation and light microscopy imaging to look for stress accelerated corrosion as well as evidence of localized corrosion. The samples from blend 3 for the carbon steel and 2.25Cr-1Mo steel showed signs of surface roughening and small pits in the bulk of the material. However, there was no distinct difference in surface characteristics between the outer diameter and inner diameter which indicated no sign of stress accelerated corrosion. Figure 8 shows the metallographic images associated with carbon steel from the blend 3 U-bends which is representative of the $2.25 \mathrm{Cr}-1$ Mo steel U-bend images as well. 

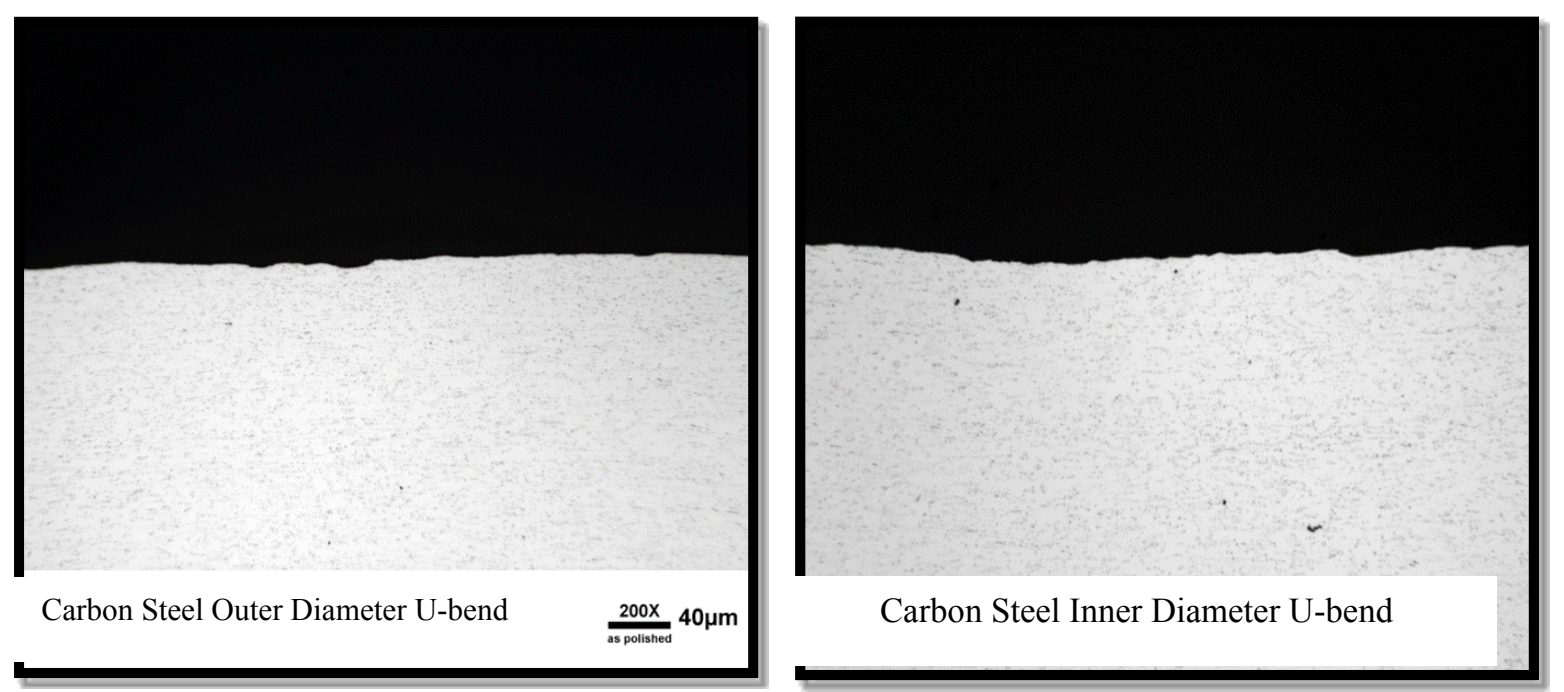

Figure 8. Micrographs near the outer (left micrograph) and inner surfaces of a carbon steel U-bend sample that were exposed to blend 3 ( $25 \%$ bio-oil).

The micrographs of the samples from blend 5 (100\% bio-oil) show distinct differences in surface attack between the vapor samples and the samples immersed in the fluid (Figure 9). The U-bend samples of carbon steel and 2.25Cr-1Mo exposed to the vapor space show evidence of pitting on the surface. The outer diameter of the U-bend contains more severe pitting than the inner diameter which also indicates stress-accelerated corrosion, yet, the U-bend samples of carbon steel and $2.25 \mathrm{Cr}-1 \mathrm{Mo}$ steel in the fluid contain uniform surface roughening. There is also no discrepancy in surface corrosion between the outer and inner diameters of the U-bends immersed in the fluid which indicates no stress accelerated corrosion. 

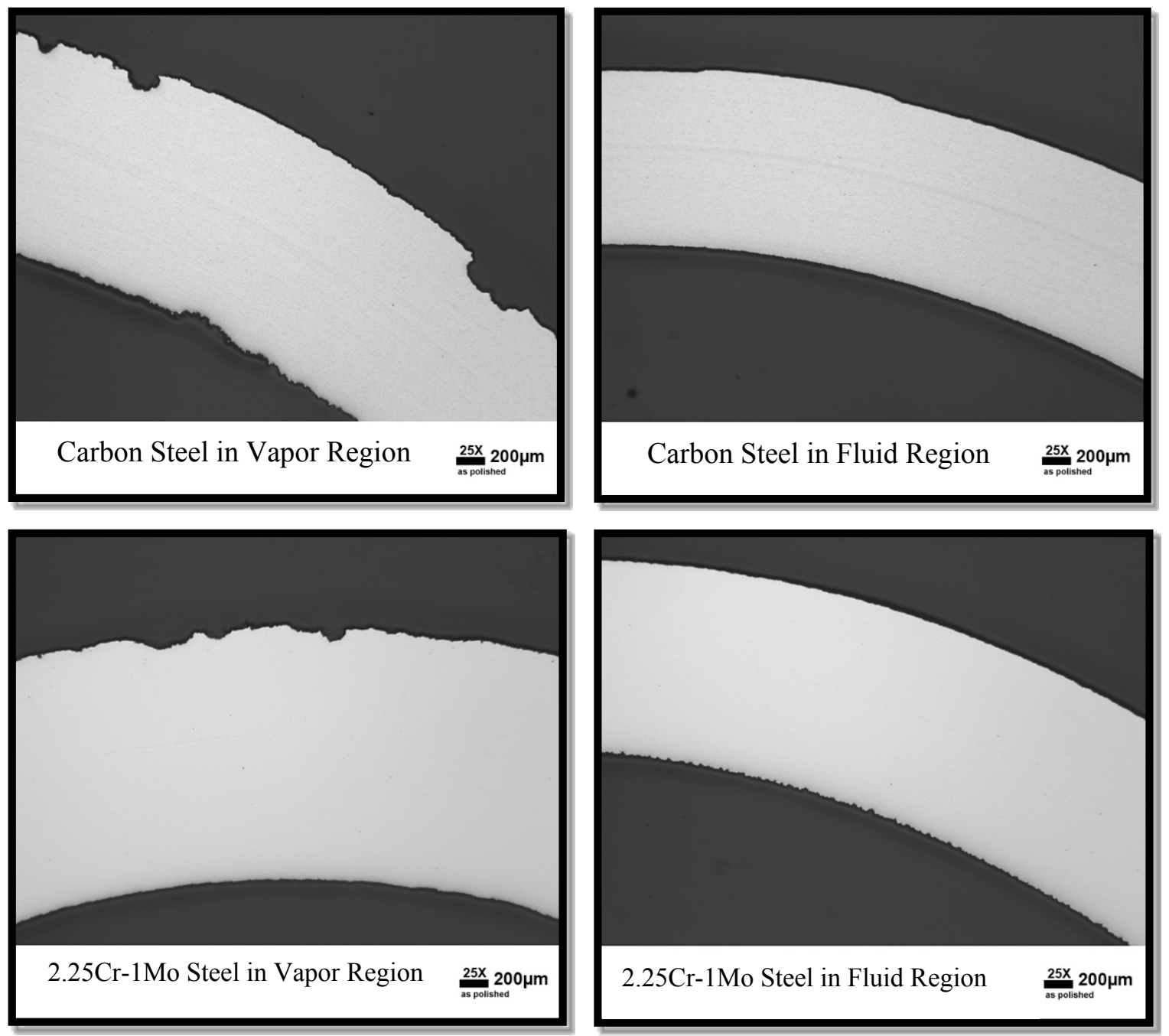

Figure 9. Micrographs of carbon steel U-bend from vapor (top left), 2.25Cr-1Mo U-bend from vapor (bottom left), carbon steel $\mathrm{U}$-bend from fluid (top right), and $2.25 \mathrm{Cr}-1 \mathrm{Mo} \mathrm{U}-$ bend from fluid (bottom right) show distinct differences in surface corrosion.

\section{DISCUSSION}

Laboratory corrosion studies showed that the corrosiveness of the blends increased significantly with increasing concentrations of bio-oil (Tables 3-4 and Figures 4-6). The corrosion rate for carbon steel and 2.25Cr-1Mo steel in the vapor space decreased between blend 3 (25\% bio-oil) and 4 (50\% bio-oil). X-ray diffraction identified a hydrated form of iron formate in the transition from blend 3 to blend 4 that may indicate that iron formate acts a barrier between the surface of these alloys and the vapor environment which inhibits the corrosion processes. However, the corrosion product is not uniform on the surface and has a high potential to react with the environment. Thus, areas where iron formate is thin or absent creates a pitting effect in the lower chromium alloys which are not able to form the protective chromium oxide on the surface. Pitting raises concern for long-term applications where pitting can propagate deeper into the material, which drastically affects the structural integrity of the material. 
The major corrosion product for carbon steel, 2.25Cr-1Mo, and 409 stainless steel immersed in the bio-oil appears to be iron formate. While formic acid is not the only corrosive constituent of bio-oil, it does play a major role in extracting iron from the bulk material of the low chromium ferrous alloys. The distinct difference between pitting of the vapor samples and uniform roughening of the fluid samples was identified via metallography (Figure 9). The relatively smooth surface of the U-bends immersed in the fluid with higher corrosion rates supports the conclusion regarding the uniform surface corrosion of carbon steel and 2.25Cr-1Mo steel immersed in bio-oil. While the magnitude of corrosion was higher in the fluid for the lower chrome alloys, the mechanism is more predictable and can be compensated for in structural design.

Corrosion of the carbon steel, $2.25 \mathrm{Cr}-1 \mathrm{Mo}$, and 409 stainless steel was more severe in the vapor space than in the fluid for blends 1 ( $8 \%$ bio-oil), 2 (19\% bio-oil), and 3 (25\% bio-oil). As the bio-oil concentration increased to $50 \%$ and above (blends 4 and 5), the fluid's corrosivity surpassed the vapor space. Further analysis of the vapor space constituents is in progress to determine why the vapor space was more aggressive in the highly diluted bio-oils. Potential interactions between the HFO and bio-oil could produce more volatile substances to effect vapor space corrosion.

As for the correlation between bio-oil concentration and corrosion rate, the conductivity of the six blends will be measured in future work. In theory, the conductivity will increase with higher concentrations of bio-oil, which in turn affects the corrosion rate. Potentially, measuring the conductivity of the blends will provide insight into the degree of corrosion for an alloy without the need for extensive laboratory corrosion studies.

\section{SUMMARY}

To replace petroleum products with biomass-derived oils, the material must be cost-effective in comparison to current petroleum processes. Low chromium content alloys are more cost-efficient than 304L and 316L stainless steels, but they have shown poor corrosion resistance to bio-oil. The dilution of the bio-oil was shown to lower the AMTAN; therefore, lower amounts of corrosive constituents are present in the liquid. Alloys that lack corrosion resistance to bio-oil show lower corrosion rates when exposed to highly diluted samples of bio-oil. By diluting bio-oil with petroleum products, materials such as 409 stainless steel can be used for storage. Low cost materials can be used for blended processing to aid the transition from petroleum products to biomass derived oils.

Key findings of this project are as follows.

1. Mixing biomass derived pyrolysis oil with HFO reduces the corrosivity and acidity of the solution.

2. 409 stainless steel performs well in blends containing up to $25 \%$ bio-oil in HFO.

3. 304L and 316L stainless steel have exceptional corrosion resistance to any concentration of bio-oil at $50^{\circ} \mathrm{C}$.

4. Iron formate is a common corrosion product on low chrome and mild steels.

5. There are distinct differences between vapor space corrosion (pitting) and corrosion of alloys immersed in bio-oil blends with HFO (uniform). 


\section{ACKNOWLEDGMENTS}

The authors wish to acknowledge the contributions of other ORNL personnel to this report: Ercan Cakmak for performing XRD analysis of the specimens, Victoria Cox for preparing specimens for light microscope examination and photography, and Adam Willoughby for constructing the testing systems. Funding for this research was provided by the U.S. Department of Energy, Office of Energy Efficiency and Renewable Energy, Bioenergy Technologies Office under contract DE-AC05-00OR22725 with UT-Battelle, LLC.

\section{REFERENCES}

1. J.R Keiser, M. P. Brady, S. A. Lewis, R. M. Connatser, D. N. Leonard, "Impact of Corrosion on Selection of Structural Materials for Thermochemical Processing Of Biomass," Proceedings of TAPPI PEERS Conference, September 14-17, 2014, Tacoma WA USA.

2. J.R Keiser, M.P. Brady, M.D. Kass, S.A Lewis, R.M. Connatser, D.N. Leonard, "Materials Compatibility Issues with Biomass-Derived Oils," Proceedings of TAPPI PEERS Conference, October 25-28, 2015, Atlanta GA USA.

3. R. A. Connatser, S. A. Lewis, J. R. Keiser, J. S. Choi, "Measuring Bio-Oil Upgrade Intermediates and Corrosive Species with Direct, Polarity-Matched Analytical Approaches," Biomass and Bioenergy, 2014, DOI: 10.1016/j.biombioe.2014.09.003.

4. J. R. Keiser, M. P. Brady, J. K. Thompson, R. M. Connatser, et al., "Bio-Oil Properties and Effects on Containment Materials," Proceedings of CORROSION 2014, March 9-13, 2014, San Antonio, Texas, USA, paper number C2014-4423.

5. Edward Wolfrum, Feedstock Conversion Interface Consortium, Process Integration Quarterly Report for 4th Quarter of FY18. National Renewable Energy Laboratory.

6. ASTM D664ASTM D664, "Standard Test Method for Acid Number of Petroleum Products by Potentiometric Titration,” ASTM International, West Conshohocken, PA, USA.

7. J.R Keiser, M. Howell, S.A Lewis, R.M Connatser, "Corrosion Studies of Raw and Treated Biomass-Derived Pyrolysis Oils," Proceedings of NACE Corrosion Conference 2012.

8. Dinesh Mohan, Charles U. Pittman Jr. and, and Philip H. Steele. "Pyrolysis of Wood/Biomass for Bio-oil: A Critical Review," Energy \& Fuels 200620 (3), 848-889. DOI: 10.1021/ef0502397.

9. J. Piskorz, D. S Scott and D. Radlein. "Composition of Oils Obtained by Fast Pyrolysis of Different Woods," Pyrolysis Oils from Biomass (16), 167-178.

10. M. Cabrini, S. Lorenzi, T. Pastore, S. Pellegrini, M. Burattini, R. Miglio, Materials 10, 3 (2017): p. 325.

11. . F. Behrendt, Y. Neubauer, M. Oevermann, B. Wilmes, N. Zobel, Chem. Eng. Technol. 31 (2008): p. 667-677. 
